\title{
Reflecting On Being an Effective Teacher in an Age of Measurement
}

\begin{abstract}
This reflective study examines what effective means in terms of teaching in secondary schools in England. The article questions whether quality assurance and observations produce better teachers or better 'fabricators'. The study explores the pressures of performativity and the resulting fabrication: the "ticking of boxes' in order to be classed as 'outstanding' and 'effective'. A journey to recapture the pleasure in teaching and learning through reflective diaries will be considered. Here the process leads to the outcome without an overemphasis on assessment criteria and performativity or extrinsic motivators which can counter intrinsic motivation and professional judgement.
\end{abstract}

Keywords: reflective diaries, noticing, motivation, performativity, fabrication, effective, measurement.

\section{Introduction}

Teachers and schools are under pressure to perform well in league tables and Ofsted inspections in order to be classed as effective (Ball, 2003; Biesta, 2009; Sahlberg, 2008). This pressure is replicated in internal quality assurance measures, performance management reviews and classroom observations. This article unpicks the importance placed upon performance regulators, particularly the terminology, such as effective, that is used to describe teachers, and the ways that a teacher can respond. It questions if such pressure helps the teacher to perform at an optimal level.

The term 'effective' is important to those working in schools as Ofsted state:

'Inspectors must judge the overall effectiveness of the school; this is the final and overarching judgement' (Ofsted, 2014).

There is no definition of what 'effectiveness' actually is, although, the document states that:

'Inspectors should first make the key judgements on: 
- the behaviour and safety of pupils at the school

- the quality of teaching in the school

- the achievement of pupils at the school'.

These considerations are graded or measured:

'In judging the school's overall effectiveness, inspectors consider whether:

The standard of education is good (grade 2), or exceeds this standard sufficiently to be judged outstanding (grade 1)'.

The term 'effectiveness' is therefore not defined as a single meaning, but is given a numerical status, and the schools and teachers are ranked according to how effective they are. When teachers and schools are graded as 'good' or 'outstanding' they are essentially being termed as effective. To be an effective teacher, according to this logic, means being a 'good' or 'outstanding' teacher, according to the Ofsted definition. To counter this, being classed as grade 3 (requires improvement) or grade 4 (inadequate) by Ofsted, is to be ineffective.

This article explores what the assessment term 'effective teacher' means and how this might be adapted to meet axiological interpretations, where effective is related to authenticity and responsive practice. To this end the study explores the pressures of performativity (Ball, 2003), and the resulting fabrication (Ball, 2000) or 'ticking of boxes' in order to be classed as 'outstanding' and 'effective' (Ofsted, 2014). However, this article is not only interested in defining effective through Ofsted viewpoints; it is also interested in the struggle to appear effective and meet these criteria. It does not question how to be an effective teacher according to Ofsted definitions, but considers how schools and teachers, including the one in this study, take summative snapshots in order to assess teachers for their performance management reviews and keep these on file for Ofsted inspections. It explores the fabrication required by the teacher in order to meet quality assurance (QA) and performance management (PM) criteria or measurement (Biesta, 2009) in order to be perceived as outstanding. It then goes on to look at what effective is to this teacher: authentic, reactive, creative and asking pupils to 
interact with their subject beyond the curriculum (and to do so themselves).

This piece starts with a feeling of oppression from the strength of the externally performative narrative, the power of the term 'effective', and the perceived knowledge of what this is. Rather than challenge this or reject it, reflective practice offers a different route, one of noticing and reacting. It could be argued that this powerful narrative becomes a productive power (Foucault \& Gordon, 1980) as the author writes and analyses her reflective diary as an agent for change.

\section{Background and methodology}

This author is a French teacher in a medium sized, co-educational comprehensive high school in the North-West of England. As quality assurance measures have increased to meet the school's perceived Ofsted requirements, I have found myself under pressure to mark in a certain way, and even in a certain coloured ink, and to increasingly teach to the test.

I am interested in intrinsic and extrinsic motivation, and how a performative, outcome-led environment can affect not only the ways a teacher structures learning, but also the enjoyment that exists when they know they are teaching well. Through reflection and small interventions I note the difference between being perceived as a good teacher in formal observations, and feeling like a good teacher at the chalk-face.

The question of whether we measure what we value or value what can be measured (Biesta, 2009) is explored as I question whether enjoyment, emotions and professional malaise are relevant to the question of what makes an effective teacher. Can reflective practice have a positive impact on teacher motivation and performance, and is it possible to prioritise professional judgement over performance indicators in order to achieve this?

The paper seeks to move away from the positivist paradigm that aspires to an absolute truth which schools and teacher are obliged to use to track student 
progress: to measure and to be measured. Whilst data, such as pupil targets; pupil books; pupil tests and formative comments, are used continuously by the teacher, the school, and Ofsted, it is not the method used for this study. Instead this study is reflective and therefore interpretivist in nature, as I locate tensions and trial mini interventions with a view to greater autonomy and enjoyment in the classroom. I have chosen this approach to delve deeper into the teacher experience of the classroom and to consider whether enjoyment has a place in a results-driven environment. This approach could be considered as catching my breath and considering how and why I teach and offering a space to reflect. In particular, to question why being assessed through extrinsic motivation strategies such as lesson observations and pupil book scrutiny has reduced my intrinsic motivation.

The need to track performance and ensure that each pupil is attaining at their optimum level has become a part of being a teacher or leader (DfE, 2015). Whilst this is questioned by many, (@BBCNews, 2016; Biesta, 2009; Illich, 1971), this study looks beyond this argument. It looks to teacher and pupil empowerment and if possible emancipation: a freedom to teach and learn in the most enjoyable manner, with the greatest chances of understanding and retention. Whilst pupil emancipation can sound appealing, emancipation is not something that can be directed, and attempting to define it as a pedagogical outcome implies further oppression (Freire, 1970) from the teacher, rather than less. Instead, as Mason (2002) notes 'change is not something that you do to other people, but something you do to yourself'. This realisation, that you can only empower yourself, but that change can take place, has been the key ontological point on which this study has been based.

This study shows the journey of a teacher struggling for freedom to act as a professional and to teach in a manner that is led by judgment rather than performance criteria. Reflective journals and critical analysis of underlying issues are used to understand what intervention might work towards this greater freedom and sense of autonomy as the teacher takes on the role of a practitioner-researcher (Mason, 2002). These journals were kept over a period of a year, and became part of my practice. The entries were made during times of emotional engagement with teaching, whether positive or negative, in order to reflect on the situation and 
on my role in it. In this way, I could distance myself from the situation but have a record of what I perceived to have happened and how this affected my motivation at the time. The record was also used to locate patterns and consider alternatives in my practice (Pollard et al., 2014).

\subsection{Noticing as a method of intervention}

Ruenzel states that when one is offered extrinsic motivators for certain behaviour, such as being labelled as 'outstanding' or 'effective', one can perform for this recognition to the detriment of one's intrinsic motivation (Bénabou \& Tirole, 2003; Lepper, Greene, \& Nisbett, 1973; Ruenzel, 2000; Ryan \& Deci, 2000). This article explores the teacher experience with a view to making small steps to regain personal professional pride, rather than seeking the 'gold star'.

In recent years, there has been increased political input into education resulting in an overhaul of secondary qualifications and assessments and teacher performance being linked to their pay (DfE, 2015) These changes have been implemented quickly and therefore the teacher's focus has been on responding to the new curriculum and the new quality assurance and performance management criteria. I have found ways to 'prove' myself as a teacher, but have not valued these new indicators or 'fabrications' (Ball, 2000). The speed of change has meant that I have reacted by finding ways to prove that I am an effective teacher according to the new criteria, but that in doing so, have not questioned their value or noticed (Mason, 2002) how these affect how I teach.

MacIntyre describes three different levels of noticing: the first is technical; the second places practical issues in a wider context of hidden assumptions and dispositions, and the third is characterised as critical or emancipatory (MacIntyre, 1993). This third level links well to my initial tensions. These three levels could link to Aristotle's three forms of knowledge, which Peace argues are the basis of curriculum ideologies (Mufti \& Peace, 2012). Where level one is productive, level two is theoretical and level three is practical (Figure 1). 


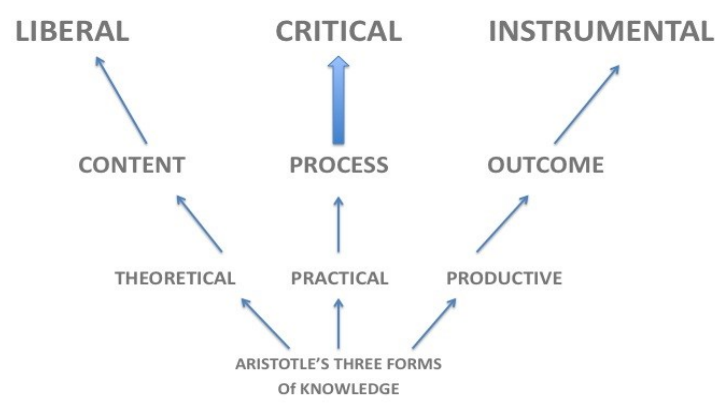

CURRICULUM IDEOLOGIES

Figure 1: Curriculum ideologies

This table is something that I will return to, as one of my recurring tensions is teaching according to outcome, which I would refer to as performance, as opposed to the teaching process, which I would refer to as practical understanding.

Mason states that to 'notice' an opportunity to react requires:

1. Being present and sensitive to the moment.

2. Having a reason to act

3. Having a different act come to mind.(Mason, 2002)

It requires a teacher to be present and aware, rather than passively acceptant, and it allows for reflection to create change.

\section{Analysis}

The reflective diaries are written to create a moment of re-entry. The emotion caught in the diaries are reactive to situations. The diary entries were analysed for deeper meaning or to find under-lying tensions. These tensions are drawn out as agents for change (Mason, 2002). The author then adapts her teaching in order to test change and find the interstices (Holland, Skinner, Lachicotte Jr., \& Cain, 2001)within the performative narrative to be classed (not passively as this requires effort to 'perform' to meet the external criteria) as effective and to also meet her own axiological criteria. The author uses her diaries 
to illustrate how this intervention is working and analyse them according to the tensions initially located within her reflections.

This article therefore explores reflection as a method of intervention and analysis. In questioning, rather than accepting the importance of Ofsted definitions of what an effective teacher is, I make changes to my practice through listening and noticing when seeking external recognition has a negative impact on my professionalism and motivation. This introspective intervention allows me to make active changes not only to the way that I teach and assesses, but also to the way that I perceive these tasks and myself as a teacher. It allows a repositioning of the teacher as a person and a part of the assessment process, in that I can also choose my own definitions of effective and how I choose to measure myself.

\section{Findings}

\subsection{Reflecting}

In terms of 'noticing' my practice, I noticed that the more that grids are created to assess my teaching and assessment, the more that I respond to find strategies in order to be easily identified as outstanding, or to gain my 'gold star' and this makes me uncomfortable.

On $3^{\text {rd }}$ February 2015, I wrote:

My daughter is unwell. I try to send her into school anyway as I spent last night marking books and wanted to hand out. In fact, yesterday I marked about 100 books.

I also got feedback from quality assurance. The department now all use the same stamps as me, and my line manager said again that she would be stealing another idea and that my marking was better than hers. I questioned to what end however, my social life or my parenting skills are being traded for this attainment. The deputy head then popped over later to that she has ordered other new stamps to make the books look pretty. Seriously, stamps! The entire 
department is copying my stamps - are these really professional issues for secondary pupils?

At the time, I considered this only in the context of quality assurance criteria. With more time to ponder on this diary entry, I can see that I was questioning my ability to be truly effective when my time is taken up proving myself. I was trying to be more than just a marking robot, albeit an 'outstanding' one. I was trying to find balance, and perhaps sanity, in my actions, and in those of others around me. I was watching others attempt to fabricate in the way that I was as a teacher, and yet, I noticed that I was perhaps prioritising this over being a good parent. I was responding to measurement and performativity, and neglecting what cannot be measured. Taking a day off work to care for a child is measured; marking is measured; pupil outcomes are measured, but the effects that marking one hundred books in one night and making choices that I am uncomfortable with, such as prioritising work over an unwell child are not measured externally. There is only a personal cost. There is a question arising, but it is not about the sanity of assessment using stamps, it is about the quality and veracity of these assessments, and an acknowledgement of the human aspect of the teacher. It brings emotions and values into being a teacher. When reading this I noticed the tensions of perceived professional performance interplaying with personal responsibilities.

This I interpreted as:

Tension 1 Work Life balance needs readjustment.

Tension 2 Quality Assurance assessment criteria does not correlate with personal values.

Tension 3 Being used as an example of good practice is uncomfortable when considering the practice being copied as a practical solution to being perceived as an effective teacher rather than of pedagogic value.

I noticed that I was concerned that my current work rate was unsustainable, 
and that others ought not to replicate it. Furthermore, I recognised that I would like to feel proud of the work that I am being applauded for, and needed to reassess how changes in my practice could address this.

\subsection{Reacting}

To reposition Mason: change is not something that you do to assessment criteria, it is something that you do to your own practice. A teacher may choose to fight the 'terrors of performativity' (Ball, 2003), or they may choose to embrace it as a part of their practice and incorporate it, rather than be led by it. A teacher could intervene by altering their perception of performance management and quality assurance importance. A teacher could perhaps reprioritise the 'who' and 'what' they want to be effective for, without compromising their status as an outstanding or effective teacher.

I decided to reconsider who I wanted to be effective for, and this was both the pupils and personal professional enjoyment. If I teach a subject that I love, which I do, how can I make pupils enjoy it more? Modern Foreign Languages are becoming less popular (Adams, 2015) both nationally and at my school. Previous research had found that one issue was using the language as 'a real means of communication'(Halliwell \& Jones, 1991).

Language acquisition is proven to be more effective through immersion (Elder \& Kim, 2005) which includes access to the media in your second language (Cook, 2008). I therefore decided to use current French chart music as background music. I usually play music whilst pupils work, choosing tracks according to their duration. These I noted were not French and were dated. Instead I played a song by 'Maitre Gims' which was in the chart in France. The class were in awe - off task, but interested, reacting with comments such as:

'Miss, this is sick!'

'Do they have music in France?'

'Can we watch the video?'

and 'What does it mean?' 
The final question meaning that their curiosity had been piqued and that they would like to understand a French song, simply because they liked it. The intervention had begun, and it was well received. I researched other songs, ensuring the content was appropriate and pupils started to make notes of the artists I was playing in the lesson, and downloading some of the songs at home. As a side effect, I noticed that I was singing along, and that I was also becoming more aware of new French culture again: I was relevant as the materials I was using were up to date. Furthermore, I was not the only one singing along in the lesson, regardless of whether or not they were getting the words right. The atmosphere had lightened, and I was resisting the urge to work according to assessment outcomes to the detriment of the classroom atmosphere.

This was an activity that simply replaced one generic resource with another. As I focus on my teaching and classroom environment more, it surprises me that this was not standard practice: it felt natural and obvious. It was used with all groups and was simple to introduce and was not merely about French culture . Some pupils in my school struggle to replicate the French accent, and the examination they find most difficult to perform well in is the 'listening'. This was addressing an assessment issue, as well as making the language feel more accessible. It was effective in engaging pupils and making them want to listen to French music. It was also effective in making them imagine French teenagers listening to music whilst completing homework or socialising, and in making them imagine themselves talking to a French teenager about music as a common interest. They were therefore not considering the GCSE speaking examination, but their 'possible self' (Dörnyei, 1998; Hazel \& Nurius, 1986) as a French speaker, engaging with people of their own age.

On a different note, this work was making me feel like an effective teacher, as the background music was creating a classroom buzz, and starting conversations about French culture and stereotypes. It carried into conversations outside the classroom. Pupils I did not teach were telling me that their friends were downloading French music, and as this music was considered good, it was 
not tainted with the negative connotations often assimilated with trying hard in an academic subject. This small act had repercussions not only for the pupils and their motivation, but also my own.

I felt emancipated from the rigidity of the curriculum, and performance management constraints as I was considering how to enhance the pupil experience in a way that could not be proven or monitored. The process strand of learning had taken precedence over the outcome and I felt there was a truth to my teaching, or that I was being true to the teacher I wanted to be, the one I had hoped to be. It must be noted, that it was the end of the school year and therefore the quality assurance of marking was less rigorous, and I had had my final performance management observation and feedback. The pupils had also had their end of year examinations and results and we were focussing on improvement. In effect, we had all performed and been assessed, and were now able to enjoy the freedom from summative feedback.

My next step was to show a film. As with the music I had used, I did not try to show a classic film in order to educate pupils about French history or culture. I chose a recent film, which was a comedy and showed it to most classes for our last two lessons before the summer break.

On $10^{\text {th }}$ July I wrote:

I can't believe what has just happened. LM has just asked me to make a note of the point in the film where we finished watching it today so that we could continue next lesson. Pupils in year 8 who have caused behavioural problems throughout the year have thanked me for the lesson. On occasions, pupils in all classes actually laughed out loud. When I asked them about watching a film with subtitles, one pupil stated they thought it would be really annoying, but it was 'alright'.

Would it be possible for me to introduce popular French films and music to pupils so that they would not consider subtitled films to be 'high-brow' when they are older? Are there other ways that I could use the media to help pupils 
engage with the language as a means of communication rather than a subject that they see as a qualification rather than a living language? Can I manage to fit this in when we are leading up to end of module key assessed tests?

This was at the end of the year, and if a member of Senior Management and Leadership Team were to pop into my lesson on a 'learning walk' I may not have been graded as effective. Showing films is frowned upon at the end of the school year, as it is hard to define what 'educational' films are. My sitting in a room and laughing along with the pupils does not make me appear to be rigorous, despite the lesson introduction, plenary and intermittent questioning. Nevertheless, I was modelling behaviour that I wanted pupils to emulate at home. As mentioned above, the listening skill is the area where pupil performance is weak, and yet, these classes were listening to French, and repeating words. French pronunciation and accent are another area of weakness, and again, watching a film allows pupils to hear real French being spoken, and seeing that it is used for humour, as well as in examination. Furthermore, they did not consider this lesson 'work'. The film had been a treat, and most pupils had chosen to engage with it, and accept my justification for its worth.

The small act of using some French media in my lessons had had a positive effect on tensions two and three, namely I felt that I had monitored myself and reacted accordingly. I was proud of finding and using current materials and bringing the language to life. I felt that its use was of pedagogic value and was willing to defend my professional judgement. Unlike the monitoring of marking criteria, where the department might choose to copy a 'trick' or fabrication (Ball, 2000) this practice is based on deeper engagement with my practice, my setting and my pupils. Using music and film is in addition to the way in which I am measured and it is therefore away from the 'gaze' (Foucault, 1977) of the department, unless I decide to share it. It is a small element of being individual in the classroom, displaying reflection, reaction, autonomy and personal authenticity which I am striving to secure. It may also be that having a 'work-life' balance, means incorporating elements of pleasure from one's personal life, for example music and film, into one's work. That in acting like a robot, I feel like a robot, but 
when I act like a person, I not only feel like one, but also respond to others and am responded to as one.

\section{Discussion}

A Centre for British Teachers Education Trust (CfBT) report on Effective teachers noted that:

'... teacher effectiveness is influenced by variations in their work, lives and identities that shape their sense of professional identity in different professional life phases. In turn, teachers' sense of professional identity influences their relative commitment and resilience as well as their capacities to manage these variations to sustain their teaching effectiveness.'

In common with the extract from my first reflective journal entry, this research acknowledges the teacher as a person who needs to juggle their professional and personal lives in order to sustain resilience and effectiveness. The study goes on the state that:

'... we should not view teacher effectiveness as an isolated characteristic of the teacher, but a consequence of many interacting factors. This research suggests that a teacher may be more or by contrast less effective in different circumstances and at different times, and thus there is a need to examine the factors that affect teachers' observed teaching behaviours, their overall teaching effectiveness, and their variation and stability over time.'(Ko, Sammons, \& Bakkum, 2013).

A teacher may not mark every book, every week or ensure that every checklist is ticked every day, but this may actually be of benefit. They may instead run an after school club, talk to a pupil or call a parent instead. To be effective one must understand how to react appropriately to events, and use one's time effectively, not prescriptively. Professional judgement is required to respond to pupil needs as they occur, reacting to 'different circumstances at different times' (Ko et al., 2013) in order to create stability. Furthermore, the authors of the study aknowledge the teacher's personal life and life stage. A teacher needs a sustainable workload, and if the balance is not correct, it can cause tensions to 
occur. These tensions draw energy, which might be used more effectively elsewhere. Rather than focus on ensuring the teacher is not measured so infrequently that a problem is missed, this study suggests that a teacher who is too frequently measured can become lost in the assessment criteria and miss appropriate ways to act and react.

CfBT also advocate Biesta's view that we should not use the term effective, without questioning for what and effective to whom (Gert Biesta, 2009; Ko et al., 2013). I had noticed that I was considering effective in terms of performance management and quality assurance grades and prioritising work according to what would be assessed, rather than what would prove more engaging. I was not the only member of staff to worry that I had little time to plan really engaging lessons rather than assess the work created by less interesting or less current materials, but through the process of 'noticing' I was noting it as something to disrupt, rather than something to bemoan.

The area of the performance and fabrication is of particular interest, as the Ofsted criteria for being an outstanding MFL teacher not only allows for teacher creativity, but encourages it. There seems to be a dichotomy between the subject specific assessment criteria, which states:

"Teachers communicate high expectations, enthusiasm and passion about their subject to pupils. They have a high level of confidence and expertise both in terms of their specialist language knowledge and their understanding of effective language learning. "(Ofsted, 2014)

and the pressured environment that can stifle it. Rather than accept that 'authenticity is replaced by plasticity' (Ball, 2000), through the interventions described in this paper, I am noticing that authenticity is possible as a part of my teaching practice and that I have agency. Through disciplined noticing, a teacher can choose the 'triumphant self' (Ball, 2000) and prioritise how they are measured, or they can choose the 'authentic self' and be more moderate in the way that they respond to being measured, instead embracing their professional judgement as valid. The power balance can be readdressed and altered. The 
teacher can acknowledge that they have ontological and axiological reasons for their practice, and that these are unlikely to be discussed as a part of the performance management process, but they are reflected in the way in which they teach and manage a classroom, and that pupil engagement and progress are still linked to this. It is possible to choose what sort of a teacher they want to be, and authenticity can be recognised within the measurement as effective, without chasing the 'gold star'. The process of being an effective teacher should lead to the outcome of being awarded the gold star, if the values are similar.

Effective teaching is graded alongside effective management. Given my diary entry in section 3.1, an inward reflection would be that the continuous assessments were affecting my motivation and sense of integrity. For a more outward reflection I would need to consider who I am performing for. If a teacher is being assessed according to Ofsted criteria, that are changed according to government policy, it could be argued that teachers are being managed by Ofsted criteria, or even those who are writing government policy. At this point it seems appropriate to reverse the judgement and question if Ofsted inspections help to promote effective teachers, or if the performance and fabrication are in fact hindering good practice through teaching according to outcome, as opposed to allowing the process to lead teachers' pedagogy. It would be interesting to drill down into what the policy writers require schools to be effective for, and for whom. This outward, or third level of reflection is one that I would like to further explore, as this is where deeper reflection can become an agent for change not only to one's own practice, but perhaps to a department, a school or more.

\section{Conclusion}

Professional intervention in my case, has been about noticing tensions and acknowledging them. It is about placing personal accountability above assessment grids, and ensuring that I act and react with professional integrity. This is something can prove is relevant to teachers who might be trying to find a professional voice within an outcome led environment. 
Using MacIntyre's three levels of noticing model, allowed me to move away from the technical aspects of teaching, towards the critical or emancipatory level, and feel emancipated from the metaphorical chains of assessment. The grids and the tick boxes had become too visible in my daily practice, and noticing the ways in which I worked towards them, helped me notice how I was moving away from considered and instinctive practice. In part, this is through requestioning hidden assumptions, such as 'quality assurance will make me a better teacher' and replacing it with the knowledge that I am gold star motivated, but that extrinsic motivation counters my intrinsic motivation. I had not taken the time to reflect on how I was reacting to these external pressures, and how I was making choices to fabricate, when I might be more effective as a teacher, and acknowledged as such, without doing so. Furthermore, I have acknowledged that education policy seems to be linked to following the productive, outcome led and therefore instrumental form of knowledge in order for education to be measurable. In noticing this, I have been able to counter how I respond in a more practical, process-led and critical way (Mufti \& Peace, 2012). This is something that could be considered for all teachers. Continued Professional Development can often focus on the 'tricks' or fabrications that can 'please' Ofsted. Reflection time would not only allow teachers to note ways they might want to change areas of their practice, but might also offer a sense of trust in their professionalism.

As the analysis above demonstrates, the discipline of noticing their own practice from a professional and personal perspective can allow a teacher to turn negative feelings into positive disruptions. Teachers may be measured and judged, but the process of noticing can be more effective to their sense of professionalism than action research, as they are capable of changing themselves, and their practice. It is possible to make the experience of being a teacher more positive, through noticing tensions and drilling down into the core reason for them, rather than finding a convenient label and dismissing it as a part of the role that is out of their control. Teachers can instead make small tweaks to their practice and to the way in which they respond to assessment guidelines and those that assess, and trust in their judgement because they have been disciplined in noticing what that judgement is. Noticing is not staffroom conversations and a 
place to vent frustrations, it requires a desire to make considered change, and in this case, a desire to create a more positive working environment and attitude through authenticity and action. It could be argued that it is a means of measuring oneself or one's practice to ensure axiological veracity, ensuring that the teacher can incorporate their personal values into the way that they teach and are measured, or that they measure what they value (Gert Biesta, 2009) within the larger political and economical picture that seems to value what it can measure' (Gert Biesta, 2009).

\section{Bibliography}

@BBCNews. (2016). Children as young as six 'stressed' about exams and tests BBC News.

Adams, R. (2015). GCSE results: fall in numbers taking foreign languages 'a cause for concern'. Retrieved from

Ball, S. (2000). Performativities and fabrications in the education economy: Towards the performative society? - Springer. doi:10.1007/BF03219719

Ball, S. (2003). The teacher's soul and the terrors of performativity

Good School/Bad School: paradox and fabrication. Journal of Education Policy, 18(2), 215-228.

Biesta, G. (2009). Good education in an age of measurement: On the need to reconnect with the question of purpose in education. Educational Assessment, Evaluation and Accountability (formerly: Journal of Personnel Evaluation in Education), 21(1), 33-46.

Bénabou, R., \& Tirole, J. (2003). Intrinsic and Extrinsic Motivation. Review of Economic Studies, 70, 489-520. doi:10.1111/1467-937x.00253

Cook, V. (2008). Second Language Learning and Language Teaching [Paperback]: Routledge; 4 edition.

DfE. (2015). STPCD 2015 Advice - Implementing-your-school_s-approach-topay.pdf.

Dörnyei, Z. n. (1998). Motivation in second and foreign language learning. In (Vol. 31, pp. 117-117).

Elder, C., \& Kim, S. H. O. (2005). Language choices and pedagogic functions in the foreign language classroom: a cross-linguistic functional analysis of teacher talk. Language Teaching Research, 9(4), 355-380.

Foucault, M. (1977). Discipline and Punish (Vol. 1).

Foucault, M., \& Gordon, C. (1980). Power-knowledge : selected interviews and other writings, 1972-1977.

Freire, P. (1970). Pedagogy of the Opressed (1996 ed.): Penguin.

Halliwell, S., \& Jones, B. (1991). On target : teaching in the target language. London: CILT.

Hazel, M., \& Nurius, P. (1986). Possible Selves. American Psychologist, 41, 954969. 
Holland, D., Skinner, D., Lachicotte Jr., W., \& Cain, C. (2001). Identity and agency in cultural worlds. Cambridge, Mass

London: Harvard University Press.

Illich, I. (1971). Deschooling society. New York.

Ko, J., Sammons, P., \& Bakkum, L. (2013). Effective Teaching: A review of Research and Evidence.

Lepper, M. R., Greene, D., \& Nisbett, R. E. (1973). Undermining children's intrinsic interest with extrinsic reward: A test of the "overjustification" hypothesis. Journal of Personality and Social Psychology, 28, 129-137.

MacIntyre, D. (1993). Theory, Theorizing and Reflection in Initial Teacher Education. In J. Calderhead \& P. Gates (Eds.), Conceptualizing Reflection in Teacher Development. London: Falmer Press.

Mason, J. (2002). Researching your own practice : the discipline of noticing: RoutledgeFalmer.

Mufti, E., \& Peace, M. (2012). Teaching and Learning and the Curriculum: A Critical Introduction.

Ofsted. (2014). Generic grade descriptors and supplementary subject-specific guidance for inspectors on making judgements during subject survey visits to schools.

Pollard, A., Black-Hawkins, K., Hodges, G. C., Dudley, P., James, M., Linklater, H., .. . Wolpert, M. A. (2014). Reflective Teaching in Schools: Bloomsbury Publishing.

Ruenzel, D. (2000). [Gold Star Junkies].

Ryan, R. M., \& Deci, E. L. (2000). Intrinsic and Extrinsic Motivations: Classic Definitions and New Directions. Contemporary educational psychology, 25(1), 54-67. doi:10.1006/ceps.1999.1020

Sahlberg, P. (2008). Rethinking accountability in a knowledge society. Journal of Educational Change, 11(1), 45-61. doi:10.1007/s10833-008-9098-2 